Original Article

\title{
Effects of combined exercise on physical fitness and neurotransmitters in children with ADHD: a pilot randomized controlled study
}

\author{
Sun-Kyoung LeE ${ }^{1)}$, Chung-Moo LeE ${ }^{1)}$, Jong-Hwan Park ${ }^{2)^{*}}$ \\ 1) Department of Physical Education, Sook-Myung Women's University, Republic of Korea \\ 2) The Dong-A Anti-Aging Research Institute, Dong-A University: 32 Daeshingongwon-Ro, Seo-Gu, \\ Busan 602-715, Republic of Korea
}

\begin{abstract}
Purpose] The purpose of the present study was to determine the effect of a jump rope and ball combined exercise program on the physical fitness the neurotransmitter (epinephrine, serotonin) levels of children with attention-deficit hyperactivity disorder. [Subjects and Methods] The subjects were 12 boys attending elementary school, whose grade levels ranged from 1-4. The block randomization method was used to distribute the participants between the combined exercise group $(n=6)$ and control group $(n=6)$. The program consisted of a 60 -min exercise (10-min warm-up, 40-min main exercise, and 10-min cool down) performed three times a week, for a total of 12 weeks. [Results] The exercise group showed a significant improvement in cardiorespiratory endurance, muscle strength, muscle endurance and flexibility after 12 weeks. A significant increase in the epinephrine level was observed in the exercise group. [Conclusion] The 12-week combined exercise program in the current study (jump rope and ball exercises) had a positive effect on overall fitness level, and neurotransmission in children with attentiondeficit hyperactivity disorder. Key words: Attention-deficit hyperactivity disorder, Exercise, Epinephrine
\end{abstract}

(This article was submitted Apr. 30, 2015, and was accepted Jun. 17, 2015)

\section{INTRODUCTION}

Attention-deficit hyperactivity disorder (ADHD) is a common neurodevelopmental disorder that affects $3-7 \%$ of school-aged children ${ }^{1)}$. This disorder is characterized by diminished abilities to pay attention and regulate impulses and behaviors ${ }^{1-3)}$.

Current research suggests that complex interactions between multiple risk factors are responsible for ADHD. Deficient or excessive supply of various neurotransmitters belonging to the amino acid group (GABA), amine group (dopamine, epinephrine, norepinephrine, serotonin, histamine, acetylcholine), and peptide group (vasopressin) are believed to be responsible for the behavioral and emotional symptoms exhibited by the affected individuals ${ }^{4}$. In particular, reduced levels of epinephrine and norepinephrine are reported to be strongly associated with ADHD symptoms ${ }^{5)}$. Furthermore, Neuro-anatomical investigations suggest that serotonin, through the orbitofrontal-striatal circuit, may regulate the behavioral domains of hyperactivity and impulsivity in $\mathrm{ADHD}^{6}$.

*Corresponding author. Jong-Hwan Park (E-mail: jpark@dau. ac.kr)

(C2015 The Society of Physical Therapy Science. Published by IPEC Inc. This is an open-access article distributed under the terms of the Creative Commons Attribution Non-Commercial No Derivatives (by-ncnd) License $<$ http://creativecommons.org/licenses/by-nc-nd/3.0/> .
Research has produced mixed results regarding the association between exercise training and neurotransmitters. An animal study conducted by Dishman ${ }^{7)}$ indicated that physical activity reduces the level of epinephrine. This is thought to be due to reduced stress perception and stimulation of the sympathetic nervous system, and an effect on the negative feedback of the HPA axis. A previous study reported the effects of a single exercise session and regular exercise on dopamine levels. Most other related studies have also reported changes in dopamine levels during prolonged exercise $^{8)}$. Combination exercise incorporates cardiovascular and resistance exercises, and improves body composition and metabolism ${ }^{9}$. This type of exercise physiologically promotes healthy growth in children ${ }^{9}$.

In addition, jump rope exercise is an effective total body exercise that requires minimal equipment, space, and time. Individuals can easily adjust the intensity and duration of the workouts by modifying the jumps height, speed, and time ${ }^{10)}$. Ball exercises develop reflexes, agility, flexibility, balance, muscular endurance, and strength, and they are the most popular exercise among children. Therefore, the purpose of the present study was to determine effect of a jump rope and ball combined exercise program on the physical fitness and neurotransmitter (epinephrine, serotonin) levels of children with ADHD.

\section{SUBJECTS AND METHODS}

Upon obtaining approval from the Institutional Review 
Table 1. Physical characteristics of the subjects

\begin{tabular}{lccccc}
\hline Group & $\mathrm{N}$ & Age (years) & Height $(\mathrm{cm})$ & Weight $(\mathrm{kg})$ & Fat $(\%)$ \\
\hline CEG & 6 & $8.83 \pm 0.98$ & $131.23 \pm 6.20$ & $28.33 \pm 4.68$ & $13.73 \pm 3.40$ \\
NEG & 6 & $8.83 \pm 0.98$ & $133.12 \pm 7.91$ & $27.32 \pm 5.31$ & $13.70 \pm 3.87$ \\
\hline
\end{tabular}

Values are $\mathrm{M} \pm \mathrm{SD}$.

CEG: combined exercise group, NEG: no exercise group.

Between-group differences were not significant (independent Student's t-test).

Table 2. Combined exercise program

\begin{tabular}{|c|c|c|c|c|c|}
\hline Order & \multicolumn{2}{|c|}{ Contents } & Period & Intensity & Time \\
\hline \multirow{2}{*}{ Warm-up } & \multicolumn{2}{|c|}{ Stretching } & $1-12$ weeks & & $10 \mathrm{~min}$ \\
\hline & $\begin{array}{c}\text { Ball } \\
(15 \mathrm{~min})\end{array}$ & $\begin{array}{c}\text { Rope-jumping } \\
\text { (25 min) }\end{array}$ & & & \\
\hline \multirow{15}{*}{$\begin{array}{l}\text { Main } \\
\text { exercise }\end{array}$} & sitting balance & non rope-jumping & & & \\
\hline & airplane arms & rope-walking & & $45-55 \%$ HRR & \\
\hline & touch down & rope-jumping & $1-4$ weeks & or & \\
\hline & right and left raise & double bounce step & & 11-12 RPE & \\
\hline & back, shoulder stretch & bounce step & & & \\
\hline & knee raise & jogging step & & & \\
\hline & heel taps & boxer step & & $55-65 \%$ HRR & \\
\hline & toe taps & scissors rock paper & 5-8 weeks & or & $40 \mathrm{~min}$ \\
\hline & leg extension & side swing & & 13-14 RPE & \\
\hline & prone bounces & curling step & & & \\
\hline & back extension & kick step & & & \\
\hline & forward & side step & & $65-75 \%$ HRR & \\
\hline & backward & couple rope-jumping & 9-12 weeks & or & \\
\hline & side by side & group rope-jumping & & 15-16 RPE & \\
\hline & limbering & group rope-jumping & & & \\
\hline $\begin{array}{l}\text { Cool- } \\
\text { down }\end{array}$ & & & $1-12$ weeks & & $10 \mathrm{~min}$ \\
\hline
\end{tabular}

Board, potential participants were recruited from K University hospital's pediatric psychiatry department located in $G$ city. A thorough information session regarding the purpose and procedures of the study was conducted, after which a written consent (drafted in accordance with IRB policy) was obtained from each volunteering parent whose child was diagnosed with ADHD. The children were diagnosed after a series of test and scale assessments conducted by medical doctor. The parents were asked to submit a detailed record of the type and amount of food consumed by the children during the previous day. The food reports were then analyzed with the use of CAN-pro 3.0 (computer aided nutritional analysis program for professionals 3.0) to determine the children's dietary habits and nutritional profiles. Subsequently, children with similar dietary habits and nutritional profiles were selected for the study.

Initially, the subjects comprised 18 boys attending elementary school, whose grade levels ranged from 1-4. The block randomization method was used to distribute the participants between a combination exercise group and a no-exercise (control) group. Six children dropped out of the study for personal reasons, leaving a total of 12 children ( 6 in the exercise group, 6 in the control group) who com- pleted the 12-week program (Table 1). The specific selection criteria were as follows 1) Male elementary school children (grade levels 1-4) who understood the study purpose and provided consent. 2) Children who obtained the approval of the tending physicians and parents for participation in the exercise program. 3) Children who met the DSM-IV ADHD diagnosis criteria. 4) Children with KEDI-WISC scores of 80 and above. 5) Children with Conners parent questionnaire scores of 16 and above. 6) Children with no current and previous history of medication or other therapies for ADHD, who were also free of other psychological disorders. 7) Children who had not participated in regular exercise for the previous 6 months.

The program consisted of a $60-\mathrm{min}$ exercise (10-min warm-up, 40-min main exercise, and 10-min cool down) performed three times a week, for a total of 12 weeks. The intensity of the main exercise was then gradually increased within $45-75 \%$ of the heart rate reserve (HRR) and 11-16 of the rating of perceived exertion (RPE). Each participant wore a heart rate monitor (Polar, sports tester, Finland). The exercise program is shown in Table 2.

For body composition, weight $(\mathrm{kg})$, height $(\mathrm{cm})$, body fat $(\%)$, muscle weight $(\mathrm{kg})$ was measured, and the pediat- 
Table 3. Changes in physical fitness at baseline and after 12 weeks

\begin{tabular}{lccc}
\hline & & pre & post \\
\hline Cardiorespiratory & CEG & $63.96 \pm 8.81$ & $71.27 \pm 8.35^{* *}$ \\
endurance (PEI) & NEG & $62.99 \pm 7.18$ & $63.72 \pm 7.08$ \\
Muscle strength & CEG & $10.63 \pm 3.24$ & $12.57 \pm 3.71^{* *}$ \\
(kg) & NEG & $11.72 \pm 2.89$ & $11.52 \pm 3.54$ \\
Muscle endurance & CEG & $20.83 \pm 9.83$ & $29.50 \pm 5.21^{* \#}$ \\
(times) & NEG & $15.67 \pm 8.36$ & $19.17 \pm 7.31$ \\
Flexibility & CEG & $9.45 \pm 4.29$ & $15.80 \pm 2.40^{* * \#}$ \\
(cm) & NEG & $6.17 \pm 5.15$ & $7.02 \pm 6.47$ \\
\hline
\end{tabular}

Values are $\mathrm{M} \pm \mathrm{SD}$

CEG: combined exercise group, NEG: no exercise group.

Significantly different from the baseline value in the same group (Paired t-test; ${ }^{*} \mathrm{p}<0.05,{ }^{* *} \mathrm{p}<0.01$ ),

Significantly different between the groups (independent t-test, ${ }^{\#} \mathrm{p}<0.05$ ).

ric BMI $\left(\mathrm{kg} / \mathrm{m}^{2}\right)$ was calculated. All the participants were instructed to avoid engaging in excessive physical activity during the $24-\mathrm{h}$ period before the measurements. They were also instructed to fast during the 4-h period before the measurements. The measurements were performed using the bioelectrical impedance analysis method with the participants wearing light clothing.

For muscle strength measurement, the participants' grip $(\mathrm{kg})$ was measured with a grip dynamometer. For muscle endurance measurement, a 1-min sit-up test, cardiorespiratory endurance and a step-test were administered. For measuring flexibility, a sit and reach flexibility-measuring tool was used (T.K.K. 5103, Japan).

The pre-exercise blood sampling required the participants to fast for a period of $10 \mathrm{~h}$. Additionally, the participants were instructed to avoid medication, caffeine, vitamins, and excessive physical activity for the 12 -h period prior to the sampling as these can affect the outcomes of blood analysis. The post-exercise blood sampling followed the same procedure with the exception of methylphenidate intake.

For both the pre- and post-exercise blood sampling, participants were instructed to rest for at least $30 \mathrm{~min}$. A disposable syringe and vacuum tubes treated with anticoagulants (SST, EDTA) were used to collect the samples. A $5 \mathrm{ml}$ sample in SST, and two $3 \mathrm{ml}$ samples (a total of $6 \mathrm{ml}$ ) in EDTA from each participant's antecubital vein were obtained.

Epinephrine analysis was performed using electrochemical detection (ECD) to measure the concentration of metabolites separated by high performance liquid chromatography (HPLC). For analysis of the serotonin level an Agilent HP1200 Series with ECD (Esa) was used.

The results were analyzed using the SPSS 18.0 statistics software. The mean (M) and standard deviation (SD) were computed for all measured parameters. In order to verify the normality of the data distributions, the KolmogorovSmirnov (goodness of fit) test was performed. In order to test the homogeneity of the major participant variables before the exercises, the independent t-test was performed. To examine the significance of pre- and post-exercise differ-
Table 4. Changes in neurotransmitter between baseline and after 12 weeks

\begin{tabular}{lccc}
\hline & & pre & post \\
\hline Epinephrine & CEG & $0.06 \pm 0.01$ & $0.12 \pm 0.06^{*}$ \\
(ng/ml) & NEG & $0.11 \pm 0.07$ & $0.12 \pm 0.09$ \\
Serotonin & CEG & $259.2 \pm 140.9$ & $265.6 \pm 101.5$ \\
(ug/l) & NEG & $285.8 \pm 83.6$ & $318.6 \pm 137.3$ \\
\hline
\end{tabular}

Values are $\mathrm{M} \pm \mathrm{SD}$

CEG: combined exercise group, NEG: no exercise group.

Significantly different from the baseline value in the same group (Paired t-test; ${ }^{*} \mathrm{p}<0.05,{ }^{* *} \mathrm{p}<0.01$ ).

ences within the groups, the paired t-test was performed. To examine the differences between the groups post-exercise, the independent t-test was performed. Significance was accepted for values of $\mathrm{p}<0.05$.

\section{RESULTS}

The results of the changes in fitness levels, both within and between the groups are shown in Table 3. The exercise group showed a significant improvement in cardiorespiratory endurance after 12 weeks $(\mathrm{p}<0.01)$. In terms of muscle strength, the exercise group showed a significant improvement $(\mathrm{p}<0.01)$ from $10.63 \pm 3.24$ to $12.57 \pm 3.71 \mathrm{~kg}$, after 12 weeks. In terms of muscle endurance, the exercise group showed a significant gain $(\mathrm{p}<0.05)$, from $20.83 \pm 9.83$ to $29.50 \pm 5.21$, after 12 weeks. The exercise group showed a significant improvement in flexibility 12 weeks later (p $<0.01$ ), from $9.45 \pm 4.29$ to $15.80 \pm 2.40 \mathrm{~cm}$. Statistically significant differences were observed in muscle endurance $(\mathrm{p}<0.05)$ and flexibility $(\mathrm{p}<0.05)$ between the two groups. However, no statistically significant differences were observed in cardiorespiratory endurance or muscle strength between the two groups.

The results of the changes in neurotransmitter levels, both within and between the groups, are shown in Table 4. The level of epinephrine in the exercise group showed a significant increase from $0.06 \pm 0.01$ to $0.12 \pm 0.06 \mathrm{ng} / \mathrm{ml}$ after the 12 -week intervention $(\mathrm{p}<0.05)$. The serotonin level in the exercise group increased from $259.20 \pm 140.98$ to 265.60 $\pm 101.51 \mu \mathrm{g} / 1$ after 12 weeks. However, no statistically significant differences were found between the epinephrine and serotonin levels in the two groups after the 12-week intervention.

\section{DISCUSSION}

The electrical signals of the nervous system are converted by neurotransmitters contained in the synapses between neurons. Serotonin and other widely known neurotransmitters, epinephrine, norepinephrine, and dopamine make up catecholamine. These neurotransmitters are involved in the stress response, and are potential causes of ADHD, and other psychological disorders such as sleep disorder, and depression $^{11)}$. According to the pathophysiological hypothesis for $\mathrm{ADHD}$, the disorder is a dysfunction of the neurotransmitters in the catecholamine group ${ }^{5)}$. Among the various methods 
that have been suggested for improving neurotransmission, exercise is known to help alleviate the symptoms caused by neurotransmitter deficiencies ${ }^{12)}$.

The results of the present study show that the combination exercise program significantly improved the epinephrine levels in the exercise group. However, no statistically significant improvement was observed in any of the neurotransmitter levels in the control group or between the two groups. Epinephrine is secreted by the adrenal medulla, and activates the central motor stimulus and peripheral vascular extension, and increases muscle enzymes. Therefore, it is more important than other hormones when sudden muscle strength and power are required ${ }^{13)}$. In the present study, the significant improvement observed in the epinephrine level of the participating children could be a result of the body's adaptation to the regular exercise performed for 12 weeks. In other words, the level of epinephrine in the blood is associated with the lactic acid level during exercise: arousal, including exercise, elevates the level of epinephrine in the body ${ }^{14)}$. Therefore, the increased level of epinephrine found in the study participants may have been a result of the body's adaptation to a higher level of arousal, stimulated and sustained during the 12-week exercise program.

On the other hand, serotonin is involved in motor control and it influences the central nervous system. Its dysfunction in the nervous system causes severe inattention and attention deficit, depression, fear, aggressive behaviors, feeding issues, sleep issues, pain regulation issues, etc. in children ${ }^{15)}$. In the present study, no significant differences in the serotonin levels were observed between the groups. However, both pre- and post-exercise levels of serotonin in the groups exceeded the normal range. In fact, the change in the post-exercise serotonin level in the exercise group was negligible. However, the change in the serotonin level in the control group was relatively significant. This could be because the effects of serotonin imbalance were mitigated by the combination exercise in the children with ADHD. Additionally, the abnormally high level of serotonin observed in the study participants may imply that children with ADHD have serotonin dysfunction, in addition to the already proven dopamine and norepinephrine dysfunctions. Further studies are required addressing this issue.

In the characteristic cognitive and emotional deficiencies, children with ADHD also exhibit motor control deficits as evidenced by poor balance, coordination, muscle strength, and reaction time ${ }^{16)}$. Therefore, increasing the fitness level of such children through physical activities is of great importance. In the present study, the cardiorespiratory endurance of the exercise group increased significantly after the 12 week intervention, indicating that the jump rope exercises and ball exercises had a positive effect on the cardiovascular capacity of the children with ADHD. Although the changes in the fitness levels observed in the control group were not significant, a trend towards an increased fitness level in the control group was seen over the study period. This could be due to the mechanisms of growth hormone and insulinlike growth factor-1 being related to different physiologic patterns of response to physical fitness in pubertal children. The present study speculates that the exercise program that combined jump rope and ball exercises had a positive effect on the cardiovascular endurance of the children with ADHD. Jump rope exercise, in particular, promotes cardiovascular health ${ }^{10)}$. Moreover, since it is a high impact exercise that requires individuals to jump up and down, it is especially effective at improving balance, coordination, accuracy, explosive muscle strength, and agility. Gappmaier et al. ${ }^{17)}$ reported that ball exercises are primarily used in physical therapies for patients with neurological problems, and that they improve the strength of the back muscles ${ }^{18)}$. The discrepancies in the findings could be due to the differences in exercise type, measuring area, participants, etc. Because of the lack of available studies on the effects of jump rope and ball combination exercise on the muscle strength of children with ADHD, further study is required to derive a more definite conclusion.

The present study had the following limitations: the participants' lifestyle factors, such as physiological and dietary/ nutritional profiles as well as sleep patterns could not be controlled in a uniform manner; the participants' psychological and genetic profiles were not similar; and the participants were limited to boys diagnosed with ADHD.

In conclusion, the 12-week combination exercise program of the present study (jump rope and ball exercises) had a positive effect on the body composition, overall fitness level, and neurotransmission of children with ADHD. Based on these findings, we suggest that combination exercise should be utilized as an effective intervention for improving the symptoms of ADHD in children.

\section{ACKNOWLEDGEMENT}

This work was supported by the Dong-A University research fund.

\section{REFERENCES}

1) American Psychiatric Association: Diagnostic and Statistical Manual of Mental Disorders, 5th ed. Arlington American Psychiatric Publishing, 2013.

2) Weyandt LL: An ADHD Primer, 2nd ed. Lawrence Erlboum Associates Publishers, 2007, p 6 (Chapter 1)

3) Seo BD, Yun YD, Kim HR, et al.: Effect of 12-week Swiss ball exercise program on physical fitness and balance ability of elderly women. J Phys Ther Sci, 2012, 24: 11-15. [CrossRef]

4) Feldman HM, Reiff MI: Clinical practice. Attention deficit-hyperactivity disorder in children and adolescents. N Engl J Med, 2014, 370: 838-846. [Medline] [CrossRef]

5) Wigal SB, Nemet D, Swanson JM, et al.: Catecholamine response to exercise in children with attention deficit hyperactivity disorder. Pediatr Res, 2003, 53: 756-761. [Medline] [CrossRef]

6) Banerjee E, Nandagopal K: Does serotonin deficit mediate susceptibility to ADHD? Neurochem Int, 2015, 82: 52-68. [Medline] [CrossRef]

7) Dishman RK: Brain monoamines, exercise, and behavioral stress: animal models. Med Sci Sports Exerc, 1997, 29: 63-74. [Medline] [CrossRef]

8) Newsholme E, Acworth I, Blomstrand E: Amino acids, brain neurotransmitters and a function link between muscle and brain that is important in sustained exercise. In: Benzi G (ed) Advances in Myochemistry, London: John Libbey Eurotext, 1987, pp 127-133.

9) Park JH, Miyashita M, Kwon YC, et al.: A 12-week after-school physical activity programme improves endothelial cell function in overweight and obese children: a randomised controlled study. BMC Pediatr, 2012, 12: 111. [Medline] [CrossRef]

10) Kawano H, Motegi $F$, Ando $T$, et al.: Appetite after rope skipping may differ between males and females. Obes Res Clin Pract, 2012, 6: e91-e174. [Medline] [CrossRef]

11) Ghuman JK, Arnold LE, Anthony BJ: Psychopharmacological and other 
treatments in preschool children with attention-deficit/hyperactivity disorder: current evidence and practice. J Child Adolesc Psychopharmacol, 2008, 18: 413-447. [Medline] [CrossRef]

12) Davis JM, Bailey SP: Possible mechanisms of central nervous system fatigue during exercise. Med Sci Sports Exerc, 1997, 29: 45-57. [Medline] [CrossRef]

13) Deschenes MR, Kraemer WJ, Maresh CM, et al.: Exercise-induced hormonal changes and their effects upon skeletal muscle tissue. Sports Med, 1991, 12: 80-93. [Medline] [CrossRef]

14) Kaur J, Spranger MD, Hammond RL, et al.: Muscle metaboreflex activation during dynamic exercise evokes epinephrine release resulting in $\beta 2$ mediated vasodilation. Am J Physiol Heart Circ Physiol, 2015, 308: H524H529. [Medline] [CrossRef]
15) Karlsson L, Tuominen L, Huotarinen A, et al.: Serotonin transporter in attention-deficit hyperactivity disorder-preliminary results from a positron emission tomography study. Psychiatry Res, 2013, 212: 164-165. [Medline] [CrossRef]

16) Jeoung BJ: The relationship between attention deficit hyperactivity disorder and health-related physical fitness in university students. J Exerc Rehabil, 2014, 10: 367-371. [Medline] [CrossRef]

17) Gappmaier E, Smith ME, Tavazoie SF, et al.: Heart rate response during 20 minutes of continuous exercise on a large therapeutic roll. Phys Ther, 1997, 77.

18) Wu WL, Chen YY, Wang CC, et al.: Influence of working memory task and time on postural control of children with attention deficit hyperactivity disorder. J Phys Ther Sci, 2014, 26: 345-347. [Medline] [CrossRef] 